\title{
Serial Cervical Length Determination in Twin Pregnancies Reveals Four Distinct Patterns with Prognostic Significance for Preterm Birth
}

\author{
Nir MELAMED, MD, MSc ${ }^{1}$, Alex PITTINI ${ }^{1}$, Liran HIERSCH, MD ${ }^{2}$, Yariv YOGEV, MD ${ }^{2}$, Steven \\ KORZENIEWSKI, Ph.D. ${ }^{3,4,5}$, Roberto ROMERO, MD, D.Med.Sci. ${ }^{3,5,6,7}$, and Jon BARRETT, \\ MD1 \\ ${ }^{1}$ Division of Maternal-Fetal Medicine, Department of Obstetrics and Gynecology, Sunnybrook \\ Health Sciences Centre, University of Toronto, Ontario, Canada \\ 2 Department of Obstetrics and Gynecology, Rabin Medical Center, Petach Tikva , and Sackler \\ Faculty of Medicine, Tel Aviv University, Tel Aviv, Israel \\ ${ }^{3}$ Perinatology Research Branch, Program for Perinatal Research and Obstetrics, Division of \\ Intramural Research, Eunice Kennedy Shriver National Institute of Child Health and Human \\ Development, $\mathrm{NIH}$, Bethesda, MD and Detroit, MI \\ ${ }^{4}$ Department of Obstetrics and Gynecology, Wayne State University School of Medicine, Detroit, \\ Michigan \\ ${ }^{5}$ Department of Epidemiology and Biostatistics, Michigan State University, East Lansing, MI \\ ${ }^{6}$ Department of Obstetrics and Gynecology, University of Michigan, Ann Arbor, MI \\ ${ }^{7}$ Center for Molecular Medicine and Genetics, Wayne State University, Detroit, MI
}

\begin{abstract}
BACKGROUND-Women with a twin gestation are at increased risk for preterm birth, and sonographic cervical length is a powerful predictor for spontaneous preterm birth. Obstetricians frequently monitor cervical length in multiple gestations; yet, the optimal method to integrate and interpret the results of serial sonographic cervical length has not been determined.
\end{abstract}

OBJECTIVE-To determine whether there are different patterns of cervical shortening in twin gestations, and whether such patterns are related to the risk of preterm birth.

\footnotetext{
Correspondence address: Nir Melamed, MD, MSc, Division of Maternal Fetal Medicine, Department of Obstetrics and Gynecology, Sunnybrook Health Sciences Center, 2075 Bayview Ave, Toronto, ON, Canada, nir.melamed@ sunnybrook.ca. Publisher's Disclaimer: This is a PDF file of an unedited manuscript that has been accepted for publication. As a service to our customers we are providing this early version of the manuscript. The manuscript will undergo copyediting, typesetting, and review of the resulting proof before it is published in its final citable form. Please note that during the production process errors may be discovered which could affect the content, and all legal disclaimers that apply to the journal pertain.

Disclosure statement: The authors report no conflict of interest.

Presentation: This paper was presented as a poster at the $35^{\text {th }}$ Annual Meeting of the Society for Maternal Fetal Medicine, Feb 2-7 , 2015, San-Diego, CA.
} 
STUDY DESIGN-We conducted a retrospective study of all women with twins followed in a single tertiary referral center during 2012-2014. All women underwent serial measurements of cervical length every 2-3 weeks starting from 14-18 weeks and until 28-32 weeks of gestation. Changes in cervical length were analyzed and classified into distinct patterns that were initially identified by visual inspection of all individual cases. Each pattern was then characterized by several parameters including information about when cervical shortening began, the rate of shortening, and whether a plateau was observed. Locally weighted regression mean profiles were generated to describe each pattern of cervical length over time. The association of these patterns with spontaneous preterm birth was determined. The specific characteristics of each pattern that further determined the risk of preterm birth were identified using multivariable logistic regression analysis.

RESULTS-We studied 441 women who had a total of 2,826 measurements of cervical length done. Overall, 4 main patterns of change in cervical length were identified: Pattern I - stable cervix $(\mathrm{n}=196)$, Pattern II - early and rapid shortening $(\mathrm{n}=18)$, Pattern III - late shortening $(\mathrm{n}=109)$, and Pattern IV - early shortening with a plateau $(n=118)$. The rate of preterm birth at $<34$ weeks was lowest in cases of Pattern I (11.7\%), followed by Pattern IV (14.4\%) and Pattern III (20.2\%), and was highest for women with Pattern II (44.4\%) ( $\mathrm{p}<0.001)$. In cases with Pattern III (late shortening), the most important factors affecting the risk of preterm birth were the shortening rate, the gestational age at the onset of cervical shortening and the initial plateau of cervical length. In the case of Pattern IV (early shortening with a plateau), it was only the new plateau at which cervical shortening stopped that was associated with the risk of preterm birth.

CONCLUSIONS-Changes in sonographic cervical length over time in twin gestations can be classified into four patterns, each associated with a different risk of preterm birth.

\section{Keywords}

prediction; prematurity; preterm labor; cervical ripening; biomarker; longitudinal study; pregnancy; ultrasound

\section{INTRODUCTION}

Preterm birth remains the main cause of neonatal mortality and morbidity in twin pregnancies. ${ }^{1-10}$ The rate of preterm birth (PTB) before 34 weeks of gestation is as high as $13 \%$ in twin pregnancies, compared with only $1 \%$ in singletons. ${ }^{7,} 11$ The early prediction of PTB in twin pregnancies is of major importance as it may assist clinicians in identifying women with twin gestations who are at high risk of PTB and who may benefit from closer monitoring, administration of corticosteroids for fetal lung maturation and other potential preventive interventions such as progesterone and cervical pessary. ${ }^{12-22}$

Sonographic measurement of cervical length (CL) at mid-gestation has been shown to be predictive of PTB in singleton 11, 23-28 and twin gestations ${ }^{12,29-39}$. This, in turn, has led to the relatively common practice of serial monitoring of CL during the second trimester in women at risk of PTB, including women with twin gestations. ${ }^{38-41}$ However, one question that needs to be answered before such practice becomes accepted into routine care relates to the optimal strategy for the integration and interpretation of the additional information 
derived from serial measurements of CL. One possible strategy for integrating and interpreting a series of measurements, which is used in the current study, is by classifying them into one of several recognized patterns.

The potential benefits of serial measurements of cervical length in twins has been addressed only by a few studies. ${ }^{34,36,42-48}$ Overall, most investigators have reported that serial measurements of CL do not improve the prediction of PTB. However, available studies have several limitations, including a small sample size and variability in the timing of CL measurement as well as the definition of cervical shortening. Furthermore, in most of these studies, the analysis of change in CL was restricted to only two sequential measurements of $\mathrm{CL}$, so that data regarding the benefit and the interpretation and integration of multiple (more than two) serial measurements of CL are lacking. Indeed, in a recent systematic review and meta-analysis on the predictive accuracy of changes in sonographic CL over time, Conde-Agudelo and Romero concluded that "the identification of distinct patterns of change in $\mathrm{CL}$ as a function of gestational age and the assessment of their predictive ability for PTB in women with singleton and twin gestations calls for further research." 49

Thus, the aims of this study were, 1) to determine if there are distinct patterns of change in sonographic cervical length serially measured over time in twin gestations, and 2) to examine the association between each pattern and preterm birth.

\section{METHODS}

This was a retrospective study of all women with twin pregnancies followed in the Twins Clinic in a single tertiary referral medical center between January 2012 and December 2014. Pregnancies complicated by any of the following conditions were excluded: less than 3 measurements of cervical length during gestation, cervical cerclage, uncertain pregnancy dating, indicated preterm delivery at $<34$ weeks for maternal or fetal indications, birth weight of either twin $<500$ gram (g), gestational age at delivery $<24$ weeks, stillbirth of one or both fetuses, monoamniotic twins, monochorionic twins with twin-to-twin transfusion syndrome (TTTS), or genetic or structural anomalies. The study was approved by the Sunnybrook Health Sciences Center Research Ethics Board.

All women were followed by a single physician (JB, a specialist in maternal fetal medicine) during the study period. All women with twin pregnancies who were followed in the Twins Clinic during the study period underwent routine transvaginal measurement of CL every 2-3 weeks starting from 14-18 weeks and until 28-32 weeks of gestation. In cases where there was evidence of cervical shortening, cervical length was monitored on a weekly basis. The decision regarding recommendation for bed rest, admission or administration of antenatal corticosteroids for fetal lung maturation was made on an individual basis. Progesterone was not used in the management of women with twins and a short cervix given the lack of a primary randomized clinical trial of vaginal progesterone in women with a twin gestation and a short cervix. ${ }^{26}$ Cervical cerclage was considered and offered in selected cases of women with marked cervical shortening or cervical dilatation when it was thought that cervical insufficiency may have played a role. ${ }^{50}$ Since our hospital is a referral center for women with twin pregnancies, several women who lived relatively far from our center had 
some of their ultrasound scans done locally (i.e., closer to their home), and in some cases the results of these scans were not always available to us.

All sonographic examinations were performed by experienced sonographers using a transvaginal approach. The measurement of cervical length was performed transvaginally after the patients had emptied their bladder and according to the standard technique. ${ }^{51}$ Briefly, the measurement of cervical length was performed in the sagittal plane, visualizing the full length of the endocervial canal from the internal to the external cervical os while exerting as little pressure with the transducer as possible. At least three measurements were obtained and the shortest measurement was recorded. The presence of cervical funneling or change in cervical length, either spontaneously or in response to fundal pressure, was routinely documented as well.

Data was extracted from the medical records and included demographic and obstetrical characteristics, chorionicity, validation of gestational age by first trimester ultrasound, complications during pregnancy, use of cervical cerclage, gestational age at delivery and neonatal characteristics. All the ultrasound reports throughout gestation were reviewed in detail for information on cervical length including the presence, shape and length of cervical funneling, length of the closed part of the cervix, and change in cervical length in response to fundal pressure.

Changes in cervical length over time for each patient were plotted, and based on visual inspection (by the primary author, NM), four patterns were identified. It should be emphasized that we had no a priori hypothesis regarding the type of patterns. Each pattern was then characterized by several parameters including information about when cervical shortening began, the rate of shortening, and whether a plateau was observed. A computerized algorithm was developed (using Microsoft Excel 2007 Visual Basic) that classified each individual trajectory of cervical length into one of the four patterns and calculated the characteristics of the pattern for each patient (more details regarding the algorithm are provided in Supplemental Figure 1). The classification accuracy of the trajectories derived from the application of the computerized algorithm (modeling) was confirmed by visual inspection of the cervical length trajectory over time for each patient, with the inspector being blinded to the pregnancy outcome. Locally weighted regression mean profiles were generated to describe each pattern of cervical length over time. The quantreg package under the $\mathrm{R}$ statistical environment was used to fit locally weighted linear quantile regression models to estimate reference biomarker quantiles (i.e., centiles) as a function of gestational age at measurement of cervical length.

Hypothesis testing was performed with the SPSS v21.0 software. Chi-square tests were used to compare proportions of PTB associated with each of the four patterns. Kaplan-Meier analysis was used to compare the survival distribution associated with each of the patterns. Cox proportional hazards regression models were used to examine magnitudes of association [hazard ratios (HR) with 95\% confidence intervals (CI)] between cervical length patterns and PTB, with and without adjustment for the index cervical length measurement. Multivariable logistic regression analysis was used to determine which of the characteristics of each cervical length pattern are associated with the risk of PTB. ANCOVA was used to 
compare the slope of the regression lines representing the rate of cervical shortening in women who did or did not deliver prematurely. Results were considered significant when the $\mathrm{P}$-value was less than 0.05 .

\section{RESULTS}

\section{Characteristics of study population}

We studied 441 women with twin pregnancies who were eligible for the study and had 2,826 measurements of cervical length done (Table 1). Eighteen women who had a cervical cerclage were excluded from the analysis. Women in the study group had a median number of 6 cervical length measurements along gestation. The rates of PTB at $<36$ weeks, $<34$ weeks, $<32$ weeks and $<30$ weeks were $41.7 \%, 15.9 \%, 7.9 \%$ and $3.6 \%$, respectively.

\section{Change in cervical length along gestation}

As the first step in determining whether the information obtained from serial cervical length measurements could identify women at risk for preterm birth, the mean cervical length as a function of gestational age was compared between women who did or did not deliver prior to 32 weeks of gestation (Figure 1; similar analysis was performed for PTB before 30 weeks and 34 weeks, data not shown). While the differences in cervical length between the two groups were relatively small at $\mathfrak{2} 0$ weeks of gestation ( 5 millimeter $(\mathrm{mm})$ ), these differences became larger at more advanced gestational ages (Figure 1). In addition, the slope of the regression line representing the change in cervical length with gestational age in women who gave birth prior to 32 weeks was significantly larger than that of women who did not $(\mathrm{P}<0.001$, Figure 1$)$. These findings imply that the information obtained from serial measurements of cervical length in twins can identify women who are more likely to deliver prematurely.

\section{Patterns of change in sonographic cervical length as a function of time}

Overall, 4 distinct patterns of change in cervical length along gestation were identified and are presented in a schematic manner in Figure 2: 1) Pattern I (stable cervix, $n=196$ (44.4\% of women), Figure $2 \mathrm{~A}$ ), where the cervix remained long and stable until at least mid third trimester. 2) Pattern II (early and rapid shortening, $n=18$ (4.1\% of women), Figure 2B), where there was a persistent shortening of cervical length starting from early second trimester at an average rate of $2.3 \pm 1.1 \mathrm{~mm} /$ week. 3) Pattern III (late shortening, $\mathrm{n}=109$ (24.7\% of women), Figure $2 \mathrm{C}$ ), where the onset of cervical shortening was noted towards late second trimester (mean gestational age of 23.5 \pm 3.3 weeks). 4) Pattern IV (early shortening with a plateau, $n=118$ ( $26.8 \%$ of women), Figure $2 \mathrm{D})$, where there was an early onset of shortening of cervical length (mean rate of $3.4 \pm 2.2 \mathrm{~mm} / \mathrm{week}$ ) until reaching a new plateau (of $24.7 \pm 7.8 \mathrm{~mm}$ at a mean gestational age of $25.0 \pm 2.9$ weeks). In most cases, the pattern could be determined for each patient by $26-28$ weeks of gestation.

Locally weighted regression lines describing the change in cervical length along gestation for women in each of the pattern groups are presented in Figure 3, superimposed on population smoothed quantiles. In women with Pattern I the cervix remained stable and remained above the $50^{\text {th }}$ percentile for gestational age until at least mid third trimester. In 
women with Pattern II (early and rapid shortening), cervical length dropped from around the $50^{\text {th }}$ percentile to the $10^{\text {th }}$ percentile, and continued to shorten along the $10^{\text {th }}$ percentile until mid third trimester. In women with Pattern III (late shortening), cervical length remained at the $50^{\text {th }}$ percentile until about late second trimester when it started to drop slowly to the $25-30^{\text {th }}$ percentile by mid third trimester. Finally, in women with Pattern IV (early shortening with plateau), the cervix shortened along the $25^{\text {th }}$ percentile until reaching a new plateau at early third trimester.

\section{Risk of preterm birth according to the specific pattern of cervical length shortening}

In order to determine whether the different patterns of change in cervical length have a prognostic value for PTB, we compared the rate of PTB associated with each of the four patterns (Figure 4). The rate of PTB at less than 36, 34 and 32 weeks was significantly different among the four groups ( $\mathrm{P}<0.001$, Figure 4$)$ : The rates were lowest for women in Pattern I (stable cervix, 30.6\%, 11.7\% and 5.1\%, respectively), highest for women with Pattern II (early and rapid shortening, $61.1 \%, 44.4 \%$ and $44.4 \%$, respectively) and intermediate for women with Pattern III (late shortening, 48.6\%, 20.2\%, and 8.3\%, respectively) or Pattern IV (early shortening with a plateau, 50.8\%, 14.4\%, and 6.8\%, respectively) (Figure 4).

\section{Risk of preterm birth per unit time (Hazard) according to the specific pattern of cervical length shortening}

Cervical length pattern groups were also associated with increased hazard (risk per unit time) for PTB $<34$ (Figure 5). Women with Pattern II (early and rapid shortening) were at more than ten times greater hazard of PTB at $<34$ weeks, whereas women with Pattern III (late shortening) had a more than twofold greater hazard for PTB at $<34$ weeks, each compared to women with Pattern I (stable cervix). By contrast, Pattern IV (early shortening with plateau) was not associated with greater hazard of PTB at $<34$ weeks, though post hoc analysis showed that women with Pattern IV were at greater hazard for PTB <36 weeks than women with Pattern I (stable cervix) (HR 1.8, 95\% CI 1.3-2.7). Multivariable adjustment for index (or first) cervical length measurement did not substantially alter these findings, nor did the exclusion of women of women who had cervical length $<25 \mathrm{~mm}$ at first measurement, indicating that the association between PTB at $<34$ weeks and the pattern of cervical length shortening was not driven by women who started out with a shorter cervical length (Figure $5)$.

\section{Characteristic features of each pattern of cervical length shortening and the risk of preterm birth}

Finally, we identified the most important characteristics within each pattern that affect the risk of PTB (Table 2). In cases of a stable cervix (Pattern I), there was no association between baseline cervical length and the risk of PTB. In women with an early and rapid shortening pattern (Pattern II), the association between shortening rate and risk of PTB achieved only borderline significance, possibly because of the small number of women displaying this pattern. In cases with late shortening (Pattern III), the most important factor affecting the risk of PTB was the shortening rate (risk increased by 2.9 fold with each additional increase of $1 \mathrm{~mm} /$ week in the shortening rate), followed by the gestational age at 
the onset of cervical shortening (risk decreased by $\sim 50 \%$ with each additional week at the onset of shortening) and the initial plateau of cervical length. In the case of early shortening with a plateau (Pattern IV), it was only the new plateau at which cervical shortening stopped that was associated with the risk of PTB (risk decreased by $\sim 20 \%$ with each additional millimeter in the new plateau of cervical length) (Table 2).

\section{COMMENT}

The aim of the current study was to determine whether there are different patterns of cervical shortening in twin gestations, and whether such patterns are related to the risk of preterm birth. Our main findings are as follows: 1) The overall rate of cervical shortening was greater in women who gave birth prematurely than in those who did not; and 2) four distinct patterns of changes in cervical length over time were observed; each pattern of cervical length shortening was associated with increased risk of PTB.

The association between a short sonographic cervical length and the risk of subsequent PTB is well-established in singleton ${ }^{11,23-28,52-61}$ and twin gestations ${ }^{12,29-40,62-64}$. Since cervical length changes over time as the time of the onset of labor approaches, we propose that cervical shortening detected with serial sonographic examinations may yield information about the risk of PTB which is not available at the time of the routine sonographic examination in the midtrimester. This implicit assumption has been the justification for performing serial cervical length measurement in women at risk for spontaneous PTB. However, rigorous evidence that such a practice improves the prediction of PTB has not been presented. Our observations provide evidence that this hypothesis is correct. Gibson et al. reported similar findings - women with twin gestations who delivered before 35 weeks of gestation had a shorter cervical length at 18 weeks ( $39.8 \mathrm{vs} .44 .5 \mathrm{~mm}$ ), 24 weeks ( 33.9 vs. $39.2 \mathrm{~mm}$ ), 28 weeks ( 37.1 vs. $38.3 \mathrm{~mm}$ ) and 32 weeks ( 28.8 vs. $35.4 \mathrm{~mm}$ ) compared with those who delivered at 235 weeks of gestation. ${ }^{34}$ In contrast, this was not observed in other studies ${ }^{34,36,42-48}$ For example, Khalil et al. reported serial measurements of cervical length in 209 women with twins at 20-23 weeks and 3-5 weeks later. ${ }^{46}$ There were no differences in the predictive value of the first cervical length measurement, the follow-up cervical length measurement, and change in cervical length between the two measurements. Similarly, Leveque et al. reported that in 120 women with twin pregnancies, there were no differences in the predictive value of cervical length at 22 weeks, cervical length at 27 weeks, and the change in cervical length between these two measurements (area under the receiver operating characteristic (ROC) curve (AUC) 0.67, 0.75 and 0.57, respectively) ${ }^{47}$ However, assessment of cervical shortening was based on only two measurements. ${ }^{34,36,43-47}$ The main difference among other studies and the present report is the number of cervical length measurements along gestation ( 6 was the median number in our study). An increased number of cervical length measurements allows a better description of changes over time than two observations.

In our study, distinct patterns of changes in cervical length over time were observed, and each pattern of cervical length shortening was associated with a different risk for PTB. In most cases, the pattern could be determined by serial measurements by $26-28$ weeks of gestation. Whether each pattern reflects a different pathogenic mechanism for PTB in twins, 
different degrees of cervical incompetence, or simply a difference in the timing of activation of cervical remodeling, requires further investigation. We recognize that the absolute differences in the rate of PTB before 34 and 32 weeks between women with Pattern I and those with Pattern III or IV were relatively small and that the statistical significance of the difference between the four patterns in these cases was mainly driven by the high rate of PTB in women with Pattern II (Figure 4). This limitation may be attributed in part to the insufficient power of the current study given the small number of women who gave birth before 34 and 32 weeks, which was further divided by 4 the Pattern groups. Still, the fact that the same relationship between the four patterns (i.e., highest rate of PTB in women with Pattern II, lowest rate in women with Pattern I, and intermediate rate in women with Pattern III and IV) was maintained across different outcome measures (i.e., PTB at $<36,34$ and 32 weeks) provides support to the idea that fitting serial measurements of cervical length into one of several patterns that are associated with varying degree of risk of PTB may be one possible strategy for the integration and interpretation of serial measurements of cervical length.

The current study has limitations. Since we were interested in the natural history of cervical length, patients who underwent a cervical cerclage were excluded from the study $(\mathrm{N}=18)$. There is little evidence to date that cervical cerclage may be effective in reducing the rate of PTB in twin gestations. Indeed, some have reported that cervical cerclage may be harmful ${ }^{22,50,65}$, although this issue has been recently revisited. ${ }^{66}$ Cervical cerclage was placed at the discretion of the treating physician, and presumably because of suspected cervical insufficiency.

Women with twin gestations and a short cervix were not treated with progesterone; therefore, we cannot determine the possible effect of vaginal progesterone on the pattern of change in cervical length. In singleton gestations, vaginal progesterone has been shown to modify the rate of cervical shortening over time. ${ }^{67}$ That this may be the case in twins is supported by the results of an individual patient meta-analysis 27 in which vaginal progesterone in women with twin gestations and a short cervix was found to reduce the rate of PTB (by 30\%) and neonatal morbidity; however, a randomized clinical trial is required to confirm such findings. ${ }^{6}$

Finally, the identification of 4 patterns is dependent upon a sample size, and it is possible that additional patterns may be identified with larger studies. Yet, the current study represents the largest on serial measurements of cervical length in asymptomatic women with twins, and the first to report the patterns of change in cervical length. Another strength of the current study is that all women were followed in a single clinic dedicated to twin pregnancies by a single physician and according to a standardized protocol, and that all sonographic measurements of cervical length were performed by experienced sonographers.

Cervical length assessment has earned a place in clinical practice, given that women with singleton gestations and a short cervix are at risk for PTB, ${ }^{11,23-28,52-61,69}$ and that vaginal progesterone can reduce such risk. ${ }^{26}$ Similarly, in women with a singleton gestation, a history of PTB and a short cervix, vaginal progesterone or cervical cerclage can reduce the rate of PTB. ${ }^{27,}{ }^{50}$ In twin gestations, sonographic cervical length is also a risk factor for 
preterm delivery. Indeed, the cervical length required to protect against a preterm delivery is greater in twins than in singletons. ${ }^{30}$ While definitive studies are needed to determine what intervention would reduce the rate of PTB in twin gestations with a short cervix, the observations presented herein may serve to counsel patients about their risk of PTB, as well as other management decisions, such as the frequency of monitoring, and the administration of corticosteroids for fetal lung maturity. For example, a recent study showed that serial monitoring of cervical length in twin gestations was associated with a more frequent administration of antenatal corticosteroids in women who delivered preterm compared to a group who did not have serial measurements of cervical length. ${ }^{70,7126,68,72}$

The pattern of change in cervical length over time can provide insight into the mechanisms responsible for PTB in twins. Cervical shortening may be informative about the timing of an insult that can activate cervical remodeling and, eventually, PTB. Therefore, further studies are required to determine whether each pattern of cervical length shortening can be attributed to a different mechanism of disease, or the same pathologic process operating at different times. It may be possible to identify biomarkers in biological fluids of pregnant women that would improve the prediction of PTB.

In summary, changes in sonographic cervical length over time occur in women with twin gestations, and some of these changes are detectable only after the standard midtrimester examination has been performed. Importantly, the specific trajectory of cervical length shortening (pattern) is related to the risk of preterm birth. Whether different therapeutic interventions (vaginal progesterone, cervical cerclage) may be more effective in patients with some patterns of cervical length shortening remains to be determined.

\section{Supplementary Material}

Refer to Web version on PubMed Central for supplementary material.

\section{ACKNOWLEDGEMENTS}

This research was supported, in part, by the Perinatology Research Branch, Division of Intramural Research, Eunice Kennedy Shriver National Institute of Child Health and Human Development, National Institutes of Health, Department of Health and Human Services (NICHD/NIH); and, in part, with Federal funds from NICHD, NIH under Contract No. HSN275201300006C.

\section{REFERENCES}

1. Robertson PA, Sniderman SH, Laros RK Jr. et al. Neonatal morbidity according to gestational age and birth weight from five tertiary care centers in the United States, 1983 through 1986. American journal of obstetrics and gynecology. 1992; 166:1629-41. discussion 41-5. [PubMed: 1615970]

2. Garite TJ, Clark RH, Elliott JP, Thorp JA. Twins and triplets: the effect of plurality and growth on neonatal outcome compared with singleton infants. American journal of obstetrics and gynecology. 2004; 191:700-7. [PubMed: 15467528]

3. Shinwell ES, Blickstein I. The risks for very low birth weight infants from multiple pregnancies. Clinics in perinatology. 2007; 34:587-97, vi-vii. [PubMed: 18063107]

4. Goldenberg RL, Culhane JF, Iams JD, Romero R. Epidemiology and causes of preterm birth. Lancet. 2008; 371:75-84. [PubMed: 18177778] 
5. Chauhan SP, Scardo JA, Hayes E, Abuhamad AZ, Berghella V. Twins: prevalence, problems, and preterm births. American journal of obstetrics and gynecology. 2010; 203:305-15. [PubMed: 20728073]

6. Vogel JP, Torloni MR, Seuc A, et al. Maternal and perinatal outcomes of twin pregnancy in 23 lowand middle-income countries. PloS one. 2013; 8:e70549. [PubMed: 23936446]

7. Martin JA, Hamilton BE, Ventura SJ, Osterman MJ, Mathews TJ. Births: final data for 2011. National vital statistics reports : from the Centers for Disease Control and Prevention, National Center for Health Statistics, National Vital Statistics System. 2013; 62:1-69, 72.

8. Burgess JL, Unal ER, Nietert PJ, Newman RB. Risk of late-preterm stillbirth and neonatal morbidity for monochorionic and dichorionic twins. American journal of obstetrics and gynecology. 2014; 210:578, e1-9. [PubMed: 24607757]

9. Wong LF, Holmgren CM, Silver RM, Varner MW, Manuck TA. Outcomes of expectantly managed pregnancies with multiple gestations and preterm premature rupture of membranes prior to 26 weeks. American journal of obstetrics and gynecology. 2015; 212:215, e1-9. [PubMed: 25218125]

10. Aduloju OP, Olofinbiyi B, Olagbuji BN, Ade-Ojo IP, Akintayo A. Obstetric outcome of twin gestations in a tertiary hospital South-western Nigeria. The journal of maternal-fetal \& neonatal medicine : the official journal of the European Association of Perinatal Medicine, the Federation of Asia and Oceania Perinatal Societies, the International Society of Perinatal Obstet. 2015; 28:900-4.

11. Iams JD, Goldenberg RL, Meis PJ, et al. The length of the cervix and the risk of spontaneous premature delivery. National Institute of Child Health and Human Development Maternal Fetal Medicine Unit Network. The New England journal of medicine. 1996; 334:567-72. [PubMed: 8569824]

12. Goldenberg RL, Iams JD, Miodovnik M, et al. The preterm prediction study: risk factors in twin gestations. National Institute of Child Health and Human Development Maternal-Fetal Medicine Units Network. American journal of obstetrics and gynecology. 1996; 175:1047-53. [PubMed: 8885774]

13. Brubaker SG, Gyamfi C. Prediction and prevention of spontaneous preterm birth in twin gestations. Seminars in perinatology. 2012; 36:190-4. [PubMed: 22713500]

14. Romero R, Yeo L, Miranda J, Hassan SS, Conde-Agudelo A, Chaiworapongsa T. A blueprint for the prevention of preterm birth: vaginal progesterone in women with a short cervix. Journal of perinatal medicine. 2013; 41:27-44. [PubMed: 23314512]

15. Makrydimas G, Sotiriadis A. Prediction of preterm birth in twins. Best practice \& research Clinical obstetrics \& gynaecology. 2014; 28:265-72. [PubMed: 24360590]

16. Conde-Agudelo A, Romero R. Prediction of preterm birth in twin gestations using biophysical and biochemical tests. American journal of obstetrics and gynecology. 2014; 211:583-95. [PubMed: 25072736]

17. Premru-Srsen T, Verdenik I, Steblovnik L, Ban-Frangez H. Early prediction of spontaneous twin very preterm birth: a population based study 2002-2012. The journal of maternal-fetal \& neonatal medicine : the official journal of the European Association of Perinatal Medicine, the Federation of Asia and Oceania Perinatal Societies, the International Society of Perinatal Obstet. 2014:1-6.

18. Romero R, Yeo L, Chaemsaithong P, Chaiworapongsa T, Hassan SS. Progesterone to prevent spontaneous preterm birth. Seminars in fetal \& neonatal medicine. 2014; 19:15-26. [PubMed: 24315687]

19. Collins A, Shennan A. A clinical opinion on how to manage the risk of preterm birth in twins based on literature review. The journal of maternal-fetal \& neonatal medicine : the official journal of the European Association of Perinatal Medicine, the Federation of Asia and Oceania Perinatal Societies, the International Society of Perinatal Obstet. 2015:1-6.

20. Liem S, Schuit E, Hegeman M, et al. Cervical pessaries for prevention of preterm birth in women with a multiple pregnancy (ProTWIN): a multicentre, open-label randomised controlled trial. Lancet. 2013; 382:1341-9. [PubMed: 23924878]

21. Goya M, De La Calle M, Pratcorona L, et al. Cervical pessary to prevent preterm birth in women with twin gestation and sonographic short cervix: a multicenter randomized controlled trial 
(PECEP-Twins). American journal of obstetrics and gynecology. 2016; 214:145-52. [PubMed: 26627728]

22. Schuit E, Stock S, Rode L, et al. Effectiveness of progestogens to improve perinatal outcome in twin pregnancies: an individual participant data meta-analysis. BJOG : an international journal of obstetrics and gynaecology. 2015; 122:27-37. [PubMed: 25145491]

23. Iams JD, Johnson FF, Sonek J, Sachs L, Gebauer C, Samuels P. Cervical competence as a continuum: a study of ultrasonographic cervical length and obstetric performance. American journal of obstetrics and gynecology. 1995; 172:1097-103. discussion 104-6. [PubMed: 7726247]

24. Berghella V, Tolosa JE, Kuhlman K, Weiner S, Bolognese RJ, Wapner RJ. Cervical ultrasonography compared with manual examination as a predictor of preterm delivery. American journal of obstetrics and gynecology. 1997; 177:723-30. [PubMed: 9369810]

25. Hassan SS, Romero R, Berry SM, et al. Patients with an ultrasonographic cervical length $<$ or $=15$ $\mathrm{mm}$ have nearly a $50 \%$ risk of early spontaneous preterm delivery. American journal of obstetrics and gynecology. 2000; 182:1458-67. [PubMed: 10871466]

26. Romero R, Nicolaides K, Conde-Agudelo A, et al. Vaginal progesterone in women with an asymptomatic sonographic short cervix in the midtrimester decreases preterm delivery and neonatal morbidity: a systematic review and metaanalysis of individual patient data. American journal of obstetrics and gynecology. 2012; 206:124, e1-19. [PubMed: 22284156]

27. Conde-Agudelo A, Romero R, Nicolaides K, et al. Vaginal progesterone vs. cervical cerclage for the prevention of preterm birth in women with a sonographic short cervix, previous preterm birth, and singleton gestation: a systematic review and indirect comparison metaanalysis. American journal of obstetrics and gynecology. 2013; 208:42, e1-42, e18. [PubMed: 23157855]

28. Barros-Silva J, Pedrosa AC, Matias A. Sonographic measurement of cervical length as a predictor of preterm delivery: a systematic review. Journal of perinatal medicine. 2014; 42:281-93. [PubMed: 24169309]

29. Imseis HM, Albert TA, Iams JD. Identifying twin gestations at low risk for preterm birth with a transvaginal ultrasonographic cervical measurement at 24 to 26 weeks' gestation. American journal of obstetrics and gynecology. 1997; 177:1149-55. [PubMed: 9396911]

30. Souka AP, Heath V, Flint S, Sevastopoulou I, Nicolaides KH. Cervical length at 23 weeks in twins in predicting spontaneous preterm delivery. Obstetrics and gynecology. 1999; 94:450-4. [PubMed: 10472876]

31. Yang JH, Kuhlman K, Daly S, Berghella V. Prediction of preterm birth by second trimester cervical sonography in twin pregnancies. Ultrasound in obstetrics \& gynecology : the official journal of the International Society of Ultrasound in Obstetrics and Gynecology. 2000; 15:288-91.

32. Guzman ER, Walters C, O'reilly-Green C, et al. Use of cervical ultrasonography in prediction of spontaneous preterm birth in twin gestations. American journal of obstetrics and gynecology. 2000; 183:1103-7. [PubMed: 11084549]

33. Vayssiere C, Favre R, Audibert F, et al. Cervical length and funneling at 22 and 27 weeks to predict spontaneous birth before 32 weeks in twin pregnancies: a French prospective multicenter study. American journal of obstetrics and gynecology. 2002; 187:1596-604. [PubMed: 12501070]

34. Gibson JL, Macara LM, Owen P, Young D, Macauley J, Mackenzie F. Prediction of preterm delivery in twin pregnancy: a prospective, observational study of cervical length and fetal fibronectin testing. Ultrasound in obstetrics \& gynecology : the official journal of the International Society of Ultrasound in Obstetrics and Gynecology. 2004; 23:561-6.

35. To MS, Fonseca EB, Molina FS, Cacho AM, Nicolaides KH. Maternal characteristics and cervical length in the prediction of spontaneous early preterm delivery in twins. American journal of obstetrics and gynecology. 2006; 194:1360-5. [PubMed: 16647922]

36. Arabin B, Roos C, Kollen B, Van Eyck J. Comparison of transvaginal sonography in recumbent and standing maternal positions to predict spontaneous preterm birth in singleton and twin pregnancies. Ultrasound in obstetrics \& gynecology : the official journal of the International Society of Ultrasound in Obstetrics and Gynecology. 2006; 27:377-86.

37. Fox NS, Saltzman DH, Klauser CK, Peress D, Gutierrez CV, Rebarber A. Prediction of spontaneous preterm birth in asymptomatic twin pregnancies with the use of combined fetal 
fibronectin and cervical length. American journal of obstetrics and gynecology. 2009; 201:313, e1-5. [PubMed: 19733285]

38. Conde-Agudelo A, Romero R, Hassan SS, Yeo L. Transvaginal sonographic cervical length for the prediction of spontaneous preterm birth in twin pregnancies: a systematic review and metaanalysis. American journal of obstetrics and gynecology. 2010; 203:128, e1-12. [PubMed: 20576253]

39. Lim AC, Hegeman MA, Huis In TVMA, Opmeer BC, Bruinse HW, Mol BW. Cervical length measurement for the prediction of preterm birth in multiple pregnancies: a systematic review and bivariate meta-analysis. Ultrasound in obstetrics \& gynecology : the official journal of the International Society of Ultrasound in Obstetrics and Gynecology. 2011; 38:10-7.

40. Sperling L, Kiil C, Larsen LU, et al. How to identify twins at low risk of spontaneous preterm delivery. Ultrasound in obstetrics \& gynecology : the official journal of the International Society of Ultrasound in Obstetrics and Gynecology. 2005; 26:138-44.

41. Multiple Pregnancy: The Management of Twin and Triplet Pregnancies in the Antenatal Period. National Collaborating Centre for Women's and Children's Health; London: Number of pages

42. Bergelin I, Valentin L. Cervical changes in twin pregnancies observed by transvaginal ultrasound during the latter half of pregnancy: a longitudinal, observational study. Ultrasound in obstetrics \& gynecology : the official journal of the International Society of Ultrasound in Obstetrics and Gynecology. 2003; 21:556-63.

43. Fox NS, Rebarber A, Klauser CK, Peress D, Gutierrez CV, Saltzman DH. Prediction of spontaneous preterm birth in asymptomatic twin pregnancies using the change in cervical length over time. American journal of obstetrics and gynecology. 2010; 202:155, e1-4. [PubMed: 19846054]

44. Hofmeister C, Brizot Mde L, Liao A, Francisco RP, Zugaib M. Two-stage transvaginal cervical length screening for preterm birth in twin pregnancies. Journal of perinatal medicine. 2010; 38:479-84. [PubMed: 20629488]

45. Oh KJ, Park KH, Jeong EH, Lee SY, Ryu A, Kim SN. The change in cervical length over time as a predictor of preterm delivery in asymptomatic women with twin pregnancies who have a normal mid-trimester cervical length. Twin research and human genetics : the official journal of the International Society for Twin Studies. 2012; 15:516-21. [PubMed: 22854157]

46. Khalil MI, Alzahrani MH, Ullah A. The use of cervical length and change in cervical length for prediction of spontaneous preterm birth in asymptomatic twin pregnancies. European journal of obstetrics, gynecology, and reproductive biology. 2013; 169:193-6.

47. Leveque C, Vayssiere C, Favre R, et al. Cervical length in asymptomatic twin pregnancies: prospective multicenter comparison of predictive indicators. The journal of maternal-fetal \& neonatal medicine : the official journal of the European Association of Perinatal Medicine, the Federation of Asia and Oceania Perinatal Societies, the International Society of Perinatal Obstet. 2015; 28:37-40.

48. Melamed N, Pittini A, Romero R, et al. Abstract 596: Serial cervical length determination in twin pregnancies reveals four distinct patterns with prognostic significance for preterm birth. Am J Obstet Gynecol (Suppl). 2015; 212:S297.

49. Conde-Agudelo A, Romero R. Predictive Accuracy of Changes in Transvaginal Sonographic Cervical Length Over Time for Preterm Birth: A Systematic Review and Meta-Analysis. American journal of obstetrics and gynecology. 2015

50. Berghella V, Odibo AO, To MS, Rust OA, Althuisius SM. Cerclage for short cervix on ultrasonography: meta-analysis of trials using individual patient-level data. Obstetrics and gynecology. 2005; 106:181-9. [PubMed: 15994635]

51. Fuchs I, Tsoi E, Henrich W, Dudenhausen JW, Nicolaides KH. Sonographic measurement of cervical length in twin pregnancies in threatened preterm labor. Ultrasound in obstetrics \& gynecology : the official journal of the International Society of Ultrasound in Obstetrics and Gynecology. 2004; 23:42-5.

52. Andersen HF, Nugent CE, Wanty SD, Hayashi RH. Prediction of risk for preterm delivery by ultrasonographic measurement of cervical length. American journal of obstetrics and gynecology. 1990; 163:859-67. [PubMed: 2206073] 
53. Heath VC, Southall TR, Souka AP, Elisseou A, Nicolaides KH. Cervical length at 23 weeks of gestation: prediction of spontaneous preterm delivery. Ultrasound in obstetrics \& gynecology : the official journal of the International Society of Ultrasound in Obstetrics and Gynecology. 1998; 12:312-7.

54. Berghella V, Kuhlman K, Weiner S, Texeira L, Wapner RJ. Cervical funneling: sonographic criteria predictive of preterm delivery. Ultrasound in obstetrics \& gynecology : the official journal of the International Society of Ultrasound in Obstetrics and Gynecology. 1997; 10:161-6.

55. Taipale P, Hiilesmaa V. Sonographic measurement of uterine cervix at 18-22 weeks' gestation and the risk of preterm delivery. Obstetrics and gynecology. 1998; 92:902-7. [PubMed: 9840546]

56. Leitich H, Brunbauer M, Kaider A, Egarter C, Husslein P. Cervical length and dilatation of the internal cervical os detected by vaginal ultrasonography as markers for preterm delivery: A systematic review. American journal of obstetrics and gynecology. 1999; 181:1465-72. [PubMed: 10601930]

57. Honest H, Bachmann LM, Coomarasamy A, Gupta JK, Kleijnen J, Khan KS. Accuracy of cervical transvaginal sonography in predicting preterm birth: a systematic review. Ultrasound in obstetrics \& gynecology : the official journal of the International Society of Ultrasound in Obstetrics and Gynecology. 2003; 22:305-22.

58. De Carvalho MH, Bittar RE, Brizot Mde L, Bicudo C, Zugaib M. Prediction of preterm delivery in the second trimester. Obstetrics and gynecology. 2005; 105:532-6. [PubMed: 15738020]

59. To MS, Skentou CA, Royston P, Yu CK, Nicolaides KH. Prediction of patient-specific risk of early preterm delivery using maternal history and sonographic measurement of cervical length: a population-based prospective study. Ultrasound in obstetrics \& gynecology : the official journal of the International Society of Ultrasound in Obstetrics and Gynecology. 2006; 27:362-7.

60. Celik E, To M, Gajewska K, Smith GC, Nicolaides KH, Fetal Medicine Foundation Second Trimester Screening G. Cervical length and obstetric history predict spontaneous preterm birth: development and validation of a model to provide individualized risk assessment. Ultrasound in obstetrics \& gynecology : the official journal of the International Society of Ultrasound in Obstetrics and Gynecology. 2008; 31:549-54.

61. Crane JM, Hutchens D. Transvaginal sonographic measurement of cervical length to predict preterm birth in asymptomatic women at increased risk: a systematic review. Ultrasound in obstetrics \& gynecology : the official journal of the International Society of Ultrasound in Obstetrics and Gynecology. 2008; 31:579-87.

62. Soriano D, Weisz B, Seidman DS, et al. The role of sonographic assessment of cervical length in the prediction of preterm birth in primigravidae with twin gestation conceived after infertility treatment. Acta obstetricia et gynecologica Scandinavica. 2002; 81:39-43. [PubMed: 11942885]

63. Klein K, Gregor H, Hirtenlehner-Ferber K, et al. Prediction of spontaneous preterm delivery in twin pregnancies by cervical length at mid-gestation. Twin research and human genetics : the official journal of the International Society for Twin Studies. 2008; 11:552-7. [PubMed: 18828739]

64. Kindinger L, Ashrafian H, Poon L, Et A. Prediction of preterm delivery with cervical length in twin pregnancy: a systematic review and meta-analysis. Reprod Sci. 2014; 21:256A.

65. American College Of O, Gynecologists. ACOG Practice Bulletin No.142: Cerclage for the management of cervical insufficiency. Obstetrics and gynecology. 2014; 123:372-9. [PubMed: 24451674]

66. Roman A, Rochelson B, Fox NS, et al. Efficacy of ultrasound-indicated cerclage in twin pregnancies. American journal of obstetrics and gynecology. 2015; 212:788, e1-6. [PubMed: 25637840]

67. O'brien JM, Defranco EA, Adair CD, et al. Effect of progesterone on cervical shortening in women at risk for preterm birth: secondary analysis from a multinational, randomized, double-blind, placebo-controlled trial. Ultrasound in obstetrics \& gynecology : the official journal of the International Society of Ultrasound in Obstetrics and Gynecology. 2009; 34:653-9.

68. Romero R. Progesterone to prevent preterm birth in twin gestations: what is the next step forward? BJOG : an international journal of obstetrics and gynaecology. 2013; 120:1-4. [PubMed: 23237263] 
69. Owen J, Yost N, Berghella V, et al. Mid-trimester endovaginal sonography in women at high risk for spontaneous preterm birth. Jama. 2001; 286:1340-8. [PubMed: 11560539]

70. Fox NS, Rebarber A, Roman AS, Klauser CK, Peress D, Saltzman DH. Combined fetal fibronectin and cervical length and spontaneous preterm birth in asymptomatic triplet pregnancies. The journal of maternal-fetal \& neonatal medicine : the official journal of the European Association of Perinatal Medicine, the Federation of Asia and Oceania Perinatal Societies, the International Society of Perinatal Obstet. 2012; 25:2308-11.

71. Lifshitz SJ, Razavi A, Bibbo C, et al. Routine cervical length and fetal fibronectin screening in asymptomatic twin pregnancies: is there clinical benefit? The journal of maternal-fetal \& neonatal medicine : the official journal of the European Association of Perinatal Medicine, the Federation of Asia and Oceania Perinatal Societies, the International Society of Perinatal Obstet. 2014; 27:566-70.

72. El-Refaie W, Abdelhafez MS, Badawy A. Vaginal progesterone for prevention of preterm labor in asymptomatic twin pregnancies with sonographic short cervix: a randomized clinical trial of efficacy and safety. Archives of gynecology and obstetrics. 2015 


\section{CONDENSATION}

Serial measurements of cervical length in women with a twin pregnancy reveal four distinct patterns with different risks for preterm birth. 


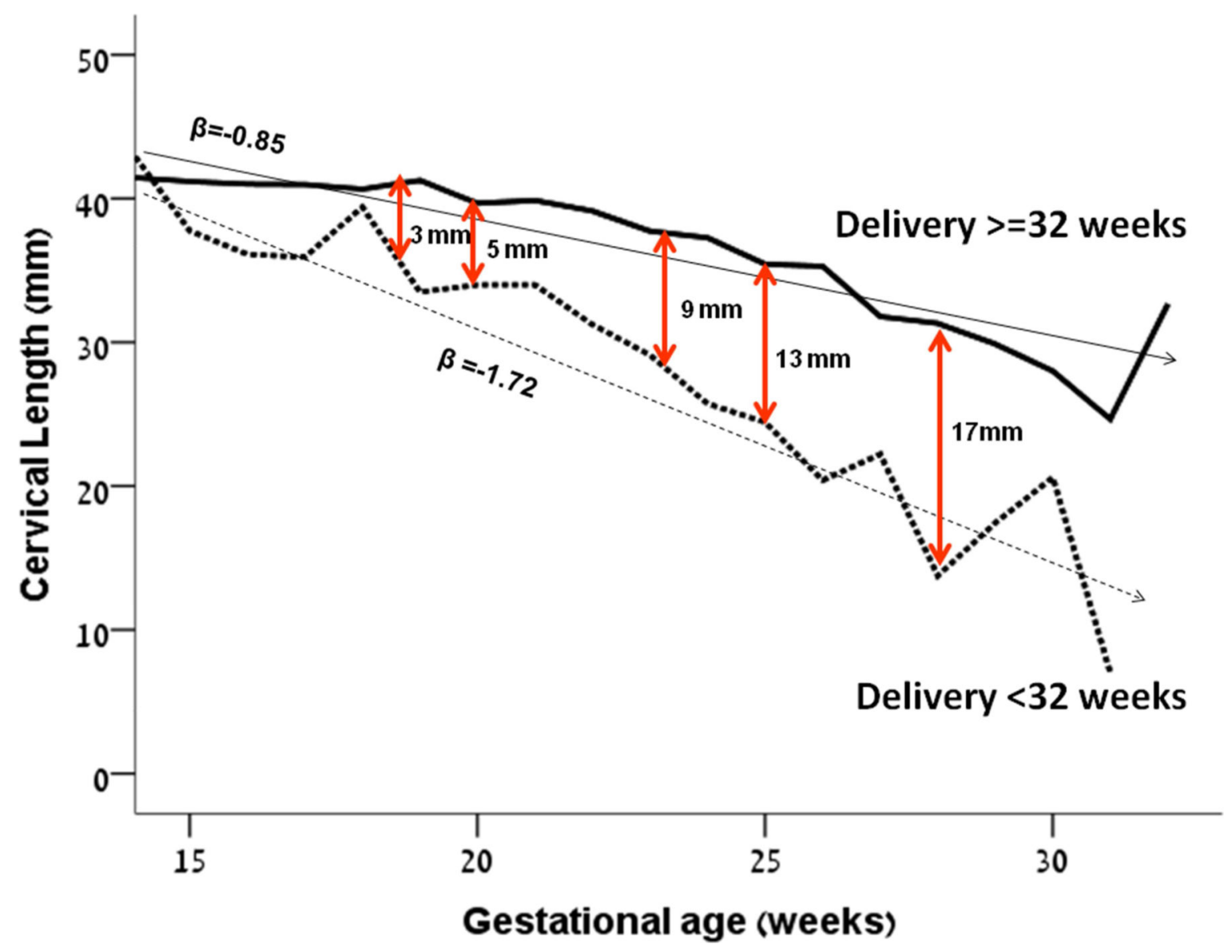

Figure 1. Cervical length as a function of gestational age according to preterm birth prior to 32 weeks

Women who did and those who did not give birth prior to 32 weeks of gestation are represented by the dashed lines and solid lines, respectively. The differences in mean cervical length between the two groups is presented at gestational age of 18, 20, 23, 25 and 28 weeks. The slope of the regression line for women who gave birth prior to 32 weeks (beta $=-1.72$ ) is significantly greater than the slope of the regression line for women who did not (beta $=-0.85, \mathrm{p}<0.001$ using ANCOVA). 

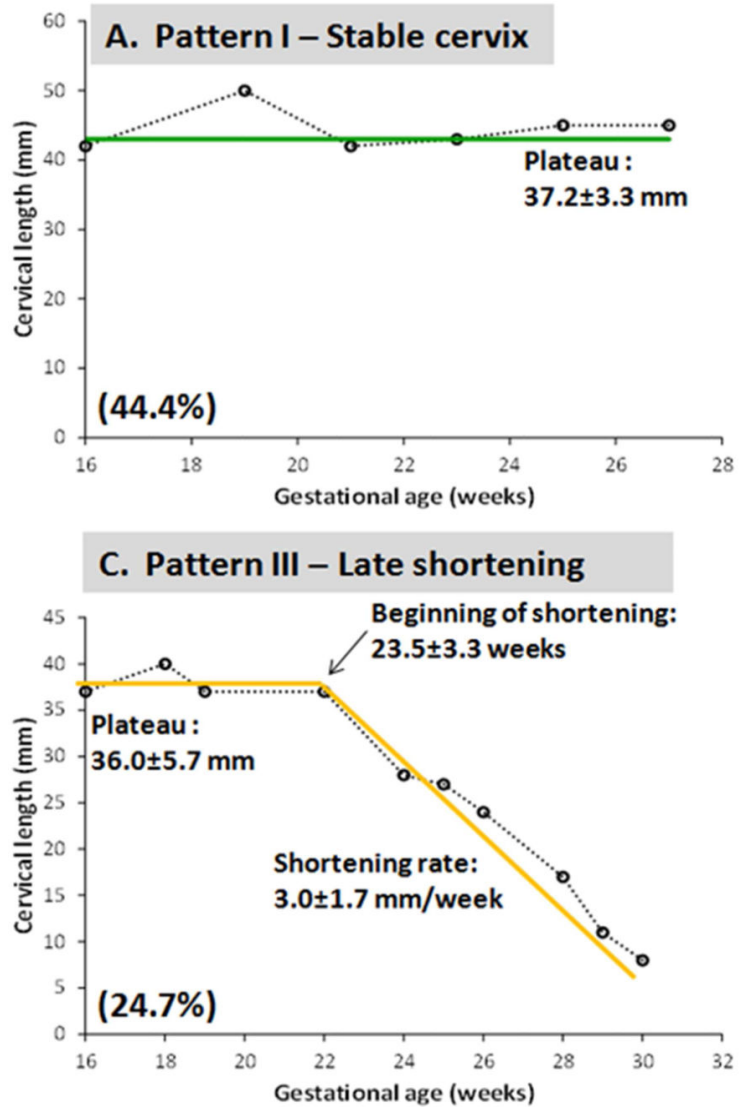

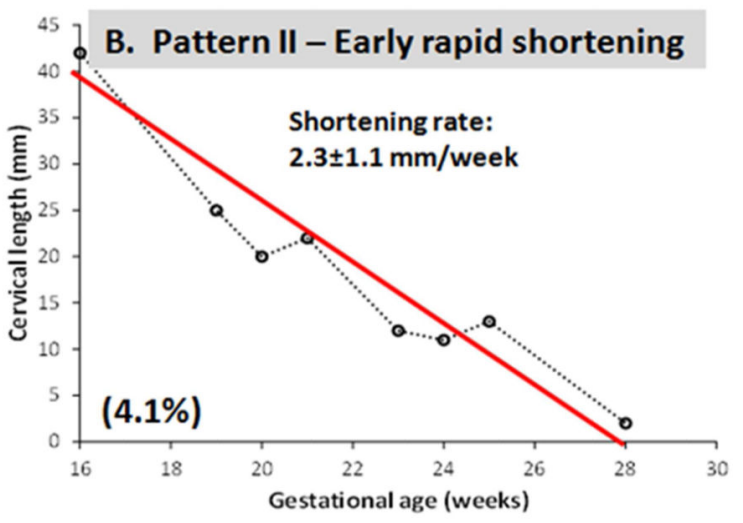

D. Pattern IV - Early shortening with plateau

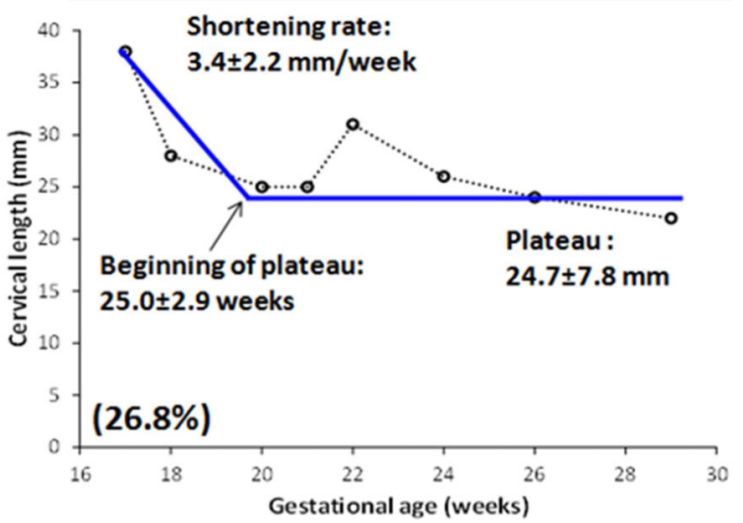

Figure 2. Patterns of change in sonographic cervical length in twin gestations Four patterns were identified: Pattern I - stable cervix (A), Pattern II - Early rapid shortening (B), Pattern III - Late shortening (C), and Pattern IV - Early shortening with plateau (D). The proportion of women in the study group having each of the distinct patterns is noted at the lower left corner of each graph. The solid lines are schematic representation of each of the patterns. The dashed lines represent examples of individual cases that were classified under the specific pattern. 


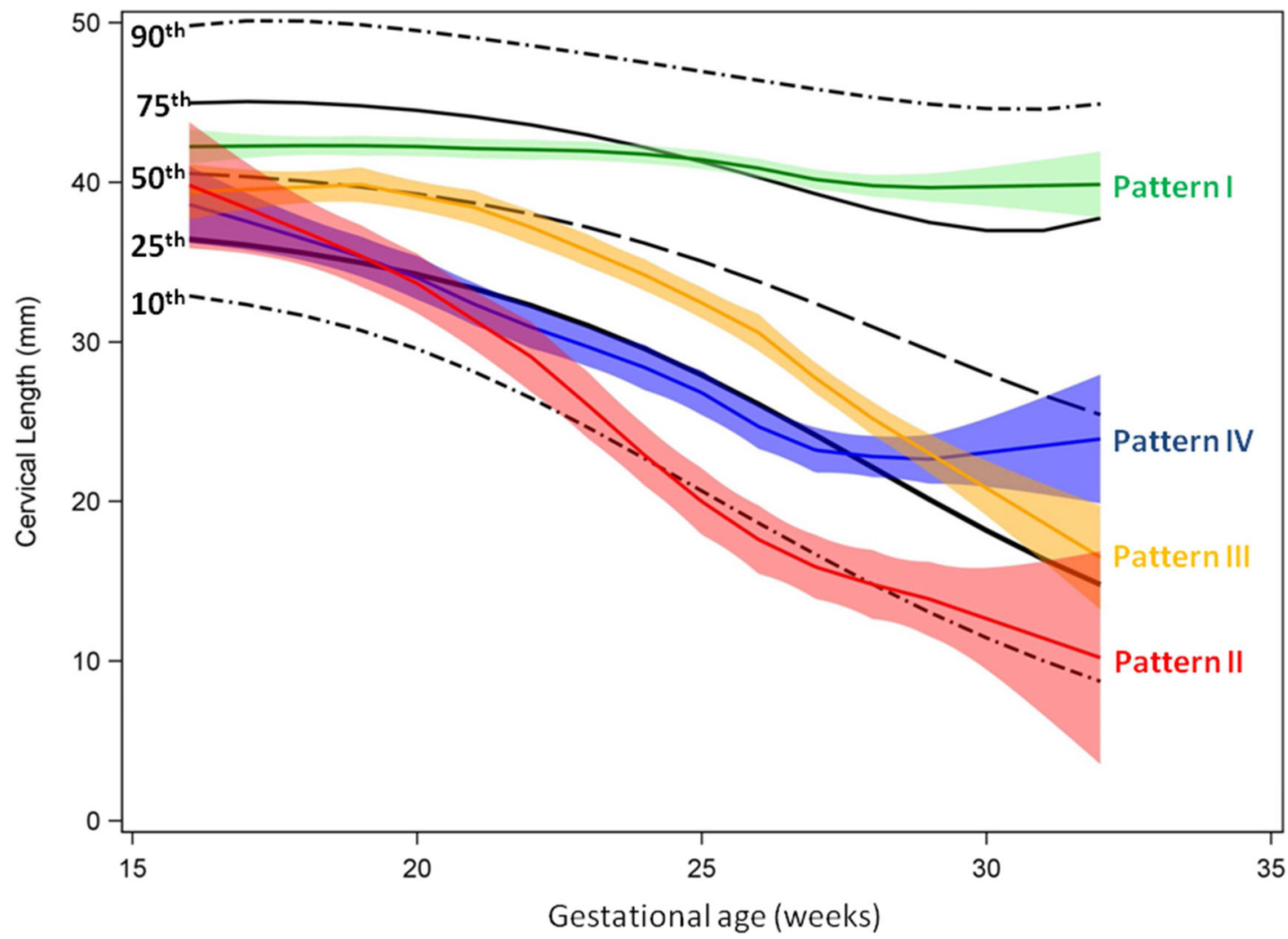

Figure 3. Mean and $95 \%$ confidence intervals of each pattern of cervical length in twin gestations determined using locally-weighted regression

The colored lines represent locally weighted regression mean profiles (95\% confidence interval bands) for each of the four curve types. The regression lines are superimposed on population smoothed quantiles (estimated by longitudinal quantile regression). 


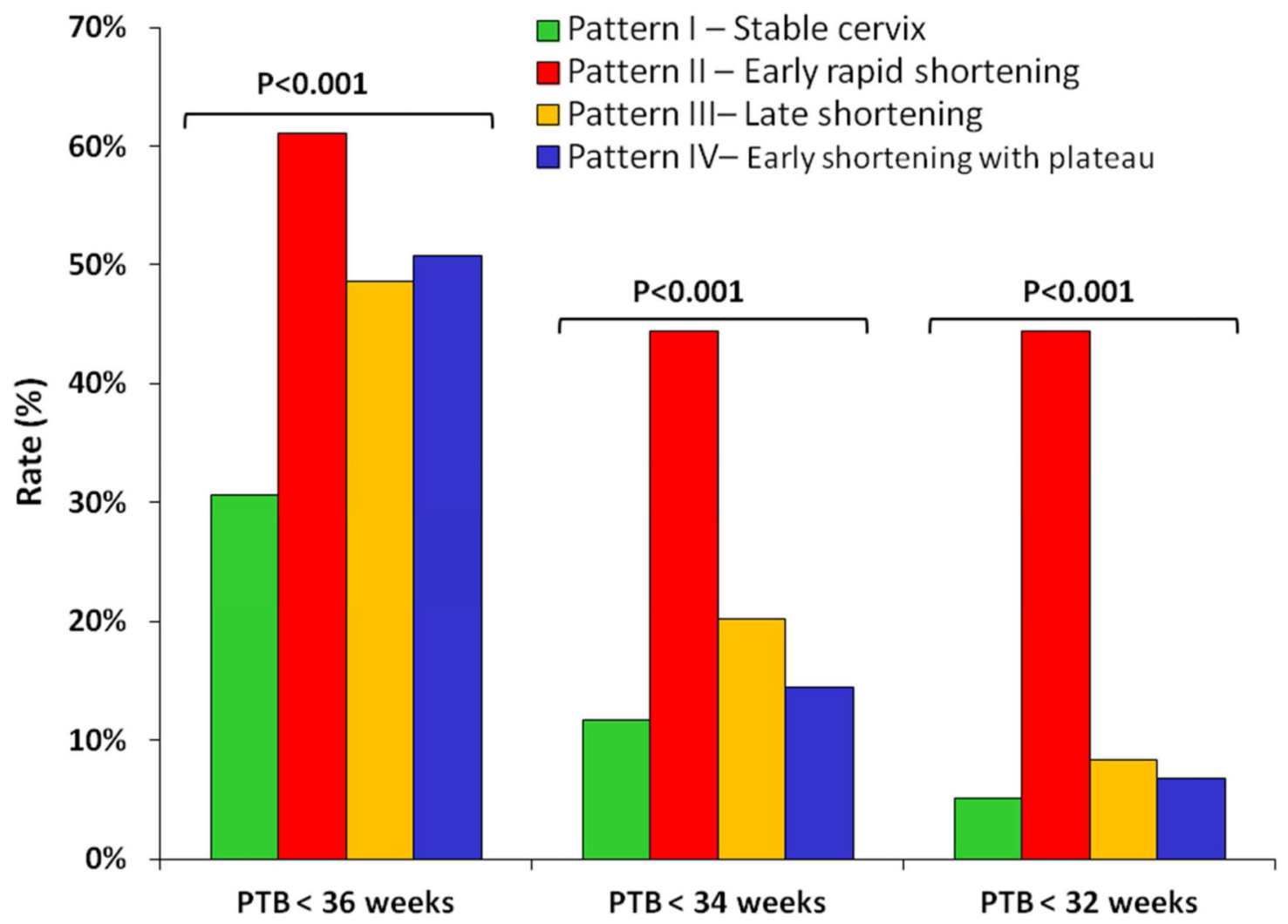

Figure 4. The rate of preterm birth associated with each of the four patterns of change in cervical length

PTB, preterm birth 


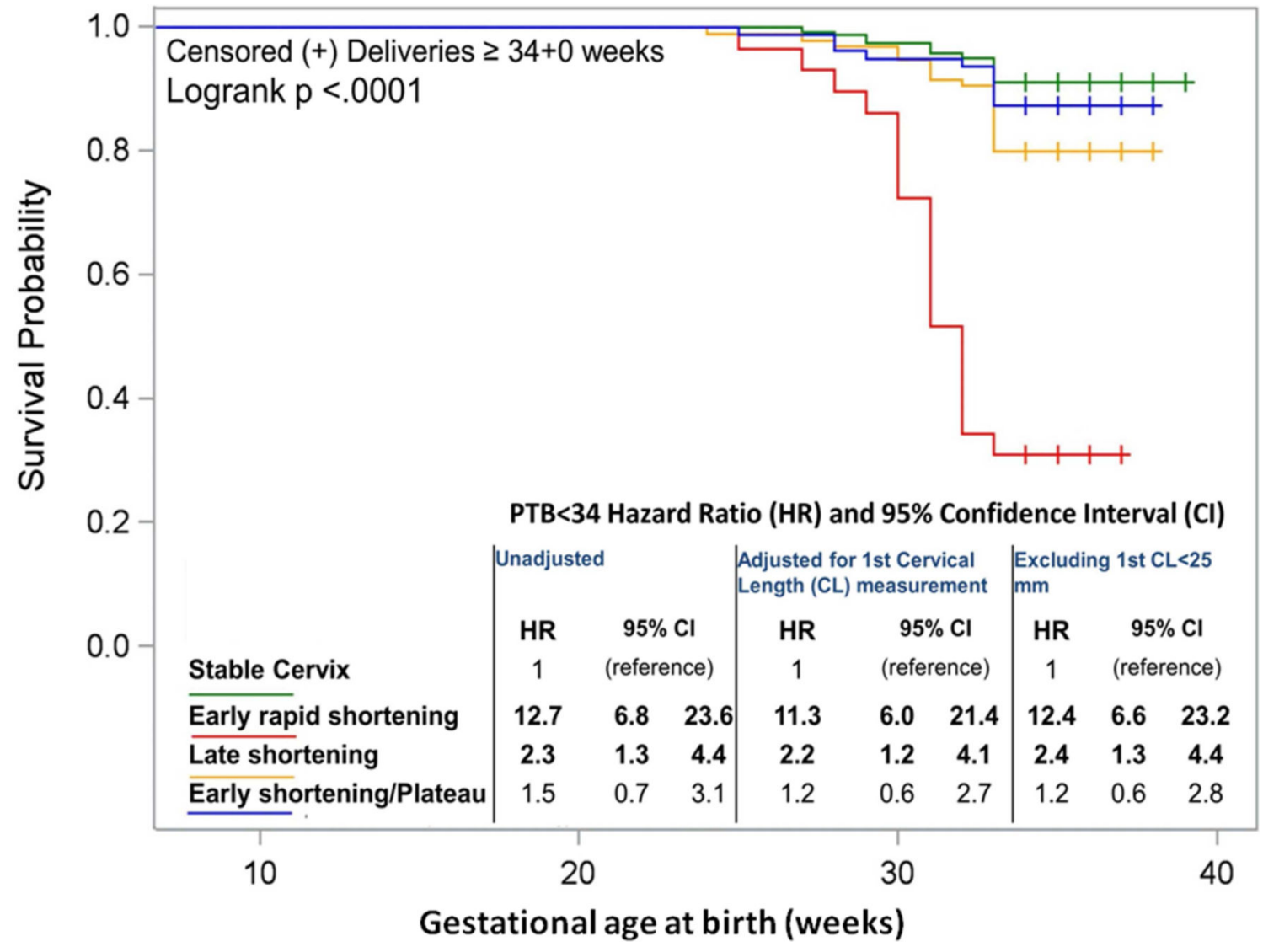

Figure 5. Survival probability expressed as a function of the pattern of cervical length shortening over time

The survival probability differed significantly as a function of the pattern of cervical length change over time when censoring patients who delivered at or after 34 weeks (Log-Rank $\mathrm{p}<0.0001)$ 


\section{Table 1}

Characteristics and outcome of the study group

\begin{tabular}{|l|l|}
\hline Characteristic (N=441) & Value \\
\hline Maternal age (years) & $32.9 \pm 4.1$ \\
\hline Nulliparity & $270(61.2)$ \\
\hline History of preterm birth & $6(1.4)$ \\
\hline Chorionicity & \\
\hline Dichorionic/Diamniotic & $358(81.2)$ \\
\hline Monochorionic/Diamniotic & $83(18.8)$ \\
\hline Number of cervical length measurements & $6(5-8)$ \\
\hline Gestational age at delivery (weeks) & $35.4 \pm 2.4$ \\
\hline$<36$ weeks * & $184(41.7)$ \\
\hline$<34$ weeks * & $70(15.9)$ \\
\hline$<32$ weeks * & $35(7.9)$ \\
\hline$<30$ weeks * & $16(3.6)$ \\
\hline Birth weight (gram) & \\
\hline Twin A & $2389 \pm 552$ \\
\hline Twin B & $2335 \pm 563$ \\
\hline Male sex & $192(43.5)$ \\
\hline Twin A & $220(49.9)$ \\
\hline Twin B & \\
\hline & \\
\hline
\end{tabular}

Values are presented as $\mathrm{N}(\%)$, median (interquartile range) or mean \pm SD unless stated otherwise.

Refers to preterm births at all gestational ages below this threshold 


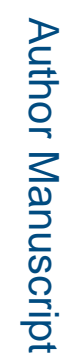

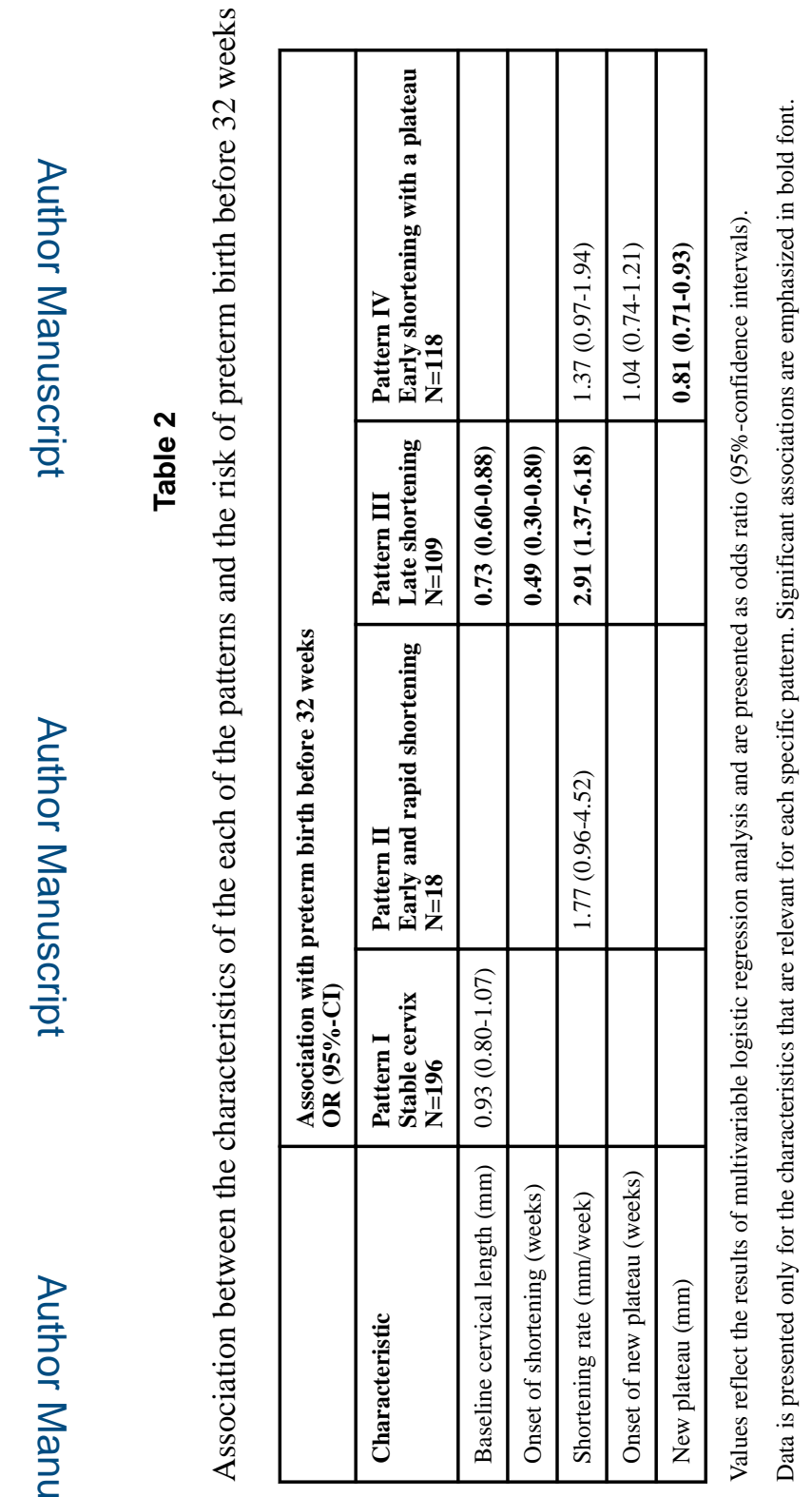

